\title{
Response of steel plates to thermal and blast load from within the fireball of an explosive event
}

\author{
L. G. Clough \& S. K. Clubley \\ Infrastructure Group, Faculty of Engineering and the Environment, \\ University of Southampton, UK
}

\begin{abstract}
Little is known of the effects of combined blast and thermal loading on structures within an explosive fireball. This paper documents and discusses the response of $2 \mathrm{~mm}$ thick steel plate within a fireball of a $41 \mathrm{~kg}$ TNT equivalent explosive. This continues the study of work investigating the synergistic response of structures to blast and thermal loads. Results from a coupled thermal and structural Finite Element Analysis (FEA) of the plates are compared with the response recorded by strain gauges and final deflected shapes. Conclusions regarding any potential synergistic response from the plates are made along with the suitability of the numerical model to be used for further coupled studies on full structural elements.
\end{abstract}

Keywords: blast, thermal, synergistic, structural response, steel.

\section{Introduction}

Two $41 \mathrm{~kg}$ TNT eq. arena trials were conducted in which six Heavy Structural Boxes (HSB) were placed at $4 \mathrm{~m}, 6 \mathrm{~m}$ and $8 \mathrm{~m}$ radial locations within and on the edge of the fireball. Thin gauge $(2 \mathrm{~mm})$ steel plates were fixed to gauged boxes with one set of fully instrumented boxes facing the blast and another (uninstrumented) facing away. The box orientation was rotated for the second trial to record the pressure/time histories on the front and rear of the boxes. Design of the trials and results from the first trial are documented in [1]. Data from the trials are discussed and compared with the FEA of the plates. Future improvements for explosive trials using the structural boxes are suggested. 
The $2 \mathrm{~mm}$ thick steel plates were modelled using a coupled (thermal and structural) non-linear, FEA software, LUSAS [2]. The models were developed to replicate the behaviour of the plates under the recorded pressures and temperatures from trials and predicted pressures from Air3D [3]. Thermal only, blast only and combined models were developed to distinguish any potential synergistic response. The plates facing towards and away from the blast were also modelled in order to help differentiate between the thermal and blast effects. The process of building and running the plate models are presented along with discussions on the deformed shapes and stresses shown in the plates.

\section{Experimental trial design}

The trials were conducted as part of an on-going programme of research. The paper "Gauging the Fireball: Simulation and Testing" [1] describes in detail the design of the arena trials and novel heavy structural boxes. This paper briefly describes the design but readers are encouraged to refer to [1] for the full trial description.

The $41 \mathrm{~kg}$ TNT eq. explosive trials were undertaken on an open air arena (Fig. 1). The HSBs were designed to withstand pressures of approximately $5 \mathrm{MPa}$ and temperatures in the region of $500^{\circ} \mathrm{C}$, to ensure they would not be damaged within the fireball of the explosion. K-Type thermocouples and Seqouia thermal flux gauges were fixed to the top of one set of the boxes. Endevco 8510c-100 pressure gauges were positioned on the front face of two of the boxes at $4 \mathrm{~m}$ and $8 \mathrm{~m}$ radial locations. The $150 \mathrm{~mm}$ diameter, $2 \mathrm{~mm}$ thick circular plate was fixed with a circular collar to the front of the box. Strain gauges and thermocouples were fixed to the rear of the steel plates to measure the deformations and temperature gradient. Figs. 2(a) and (b) shows images of the HSBs.

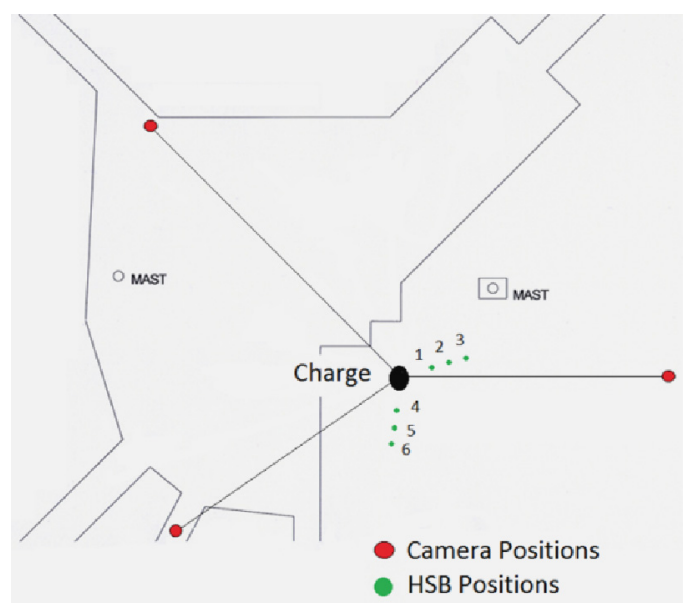

Figure 1: Plan of arena trial. 


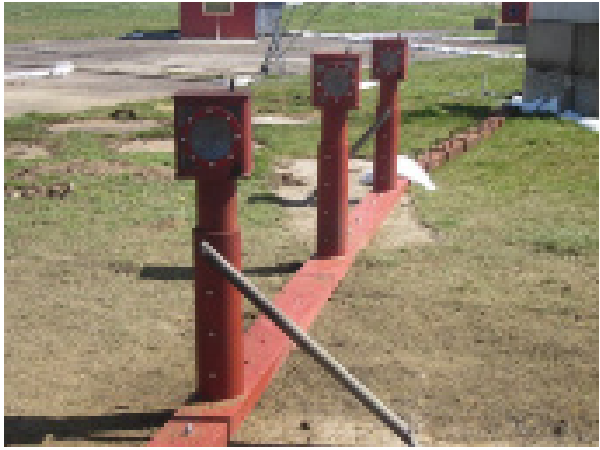

(a)

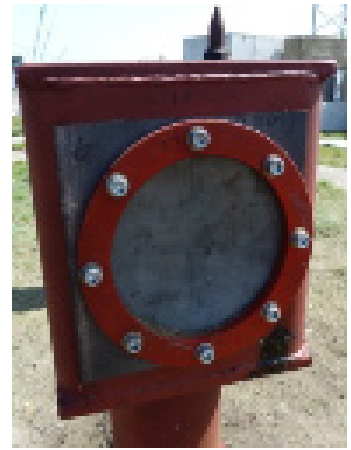

(b)

Figure 2: $\quad$ (a) Heavy structural boxes (HSB); (b) Front of HSB.

Data cables from the gauges were fed through a hole in the base of the boxes into circular hollow sections (CHS) which the boxes were mounted upon. For the second trial the box orientation was rotated through 180 degrees.

The steel used was Hot Rolled Steel for Forming (BSEN 10111:DD11), this has a lower strength than a typical structural steel, with a yield strength $162 \mathrm{MPa}$ and ultimate strength of 266MPa. The Young's modulus was 202GPa. Low strength steel was selected to increase the likelihood of a plastic response. Table 1 shows coupon tensile test data from the steel plate samples.

Table 1: $\quad$ Tensile test data.

\begin{tabular}{|l|l|l|l|l|}
\hline Sample & $\begin{array}{c}\text { Yield strength/0.2\% proof } \\
\text { stress (MPa) }\end{array}$ & $\begin{array}{c}\text { Ultimate tensile } \\
\text { strength (MPa) }\end{array}$ & $\begin{array}{c}\text { Fracture } \\
\text { (MPa) }\end{array}$ & $\begin{array}{c}\text { Young's } \\
\text { Modulus (GPa) }\end{array}$ \\
\hline 1.1 & $160 / 165$ (Low Strain Rate) & 260 & 204 & 212 \\
\hline 2.1 & $152 / 156$ & 266 & 260 & 213 \\
\hline 3.1 & $160 / 167$ & 269 & 266 & 200 \\
\hline 1.2 & $156 / 164$ & 267 & 260 & 213 \\
\hline 2.2 & $152 / 154$ & 266 & 260 & 183 \\
\hline 3.2 & $162 / 167$ & 270 & 266 & 188 \\
\hline Average & $157 / 162$ & 266 & 253 & 202 \\
\hline
\end{tabular}

\section{Trial results}

The following section describes and compares the gauge results from both trials compared with numerical models. Fig. 3(a) and (b) shows still images immediately after detonation taken by phantom high speed cameras ( 1 frame $/ 200 \mu \mathrm{s}$ ). The fireball reached a maximum diameter of approximately $12.5 \mathrm{~m}$ at $39 \mathrm{msec}$.

\subsection{Temperature}

Fig. 4 shows the recorded temperatures from the first and second trials. The temperature profiles for each trial are comparable. At $4 \mathrm{~m}$ the peak temperature is 


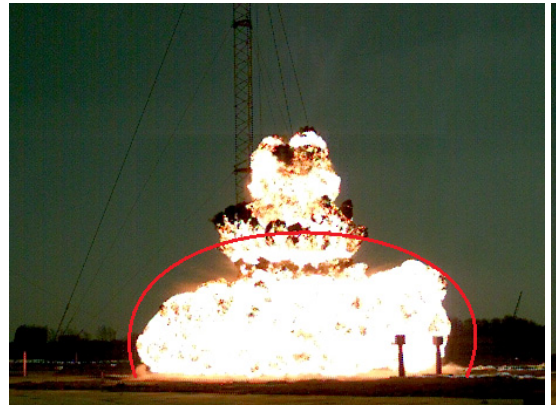

(a)

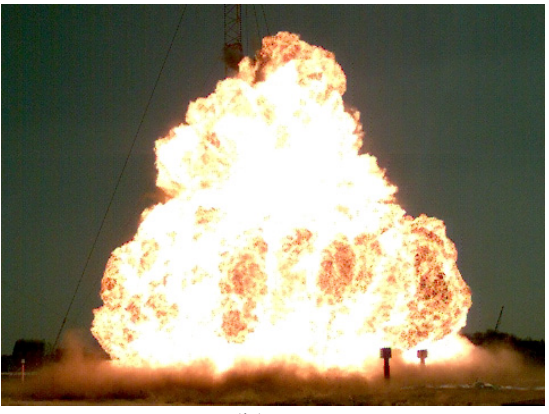

(b)

Figure 3: (a) Fireball at 5.39msec after ignition; (b) Fireball at $39 \mathrm{msec}$.

higher and the temperature decrease is slower for the first $\left(480^{\circ} \mathrm{C}\right)$ than the second trial $\left(465^{\circ} \mathrm{C}\right)$. At $6 \mathrm{~m}$ the peak temperatures were $106^{\circ} \mathrm{C}$ and $64^{\circ} \mathrm{C}$ for the first and second trial respectively. At $8 \mathrm{~m}$ the peak temperature for the first trial was $75^{\circ} \mathrm{C}$ compared to $46^{\circ} \mathrm{C}$ for the second. The differing values are likely due to the uneven propagation and highly volatile nature of the fireball.

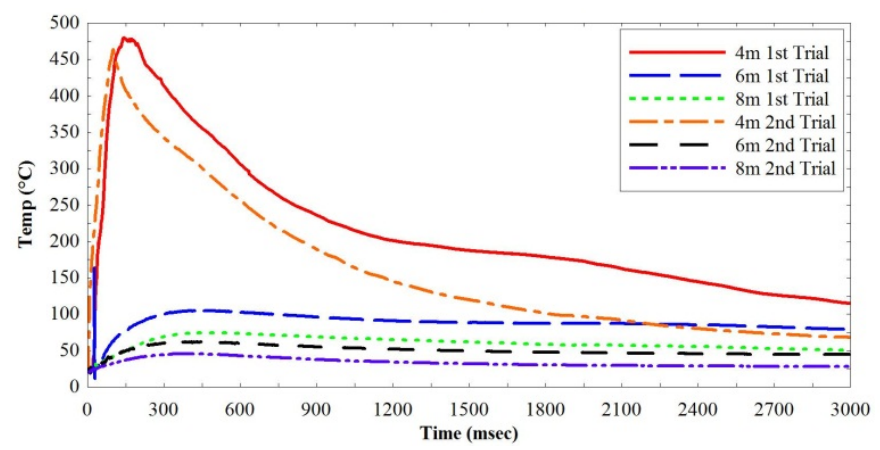

Figure 4: $\quad$ External temperature at $4 \mathrm{~m}, 6 \mathrm{~m}$ and $8 \mathrm{~m}$ radial positions.

Fig. 5 shows the recorded internal temperatures behind the steel plates. Initial temperatures of $28.1^{\circ} \mathrm{C}$ and $23.8^{\circ} \mathrm{C}$ were recorded during the first and second trials respectively. These recorded temperatures are aligned in Fig. 5 to observe the differential over time. The temperature increase to $3 \mathrm{secs}$ at $4 \mathrm{~m}$ was $8.2^{\circ} \mathrm{C}$ and $3.75^{\circ} \mathrm{C}$ for the first trial and second trial respectively. The difference in temperature increase between the two trials can be attributed to the plate orientation. The plates faced towards the charge in the first trial and away during the second trial. The thermal load from any explosive fireball can be transferred through the air by both radiation and convection. Shadowing severely affects the heat transfer through radiation but less so through convection. The lower temperature on the plates facing away is due to shadowing of both radiated and convected thermal energy. 


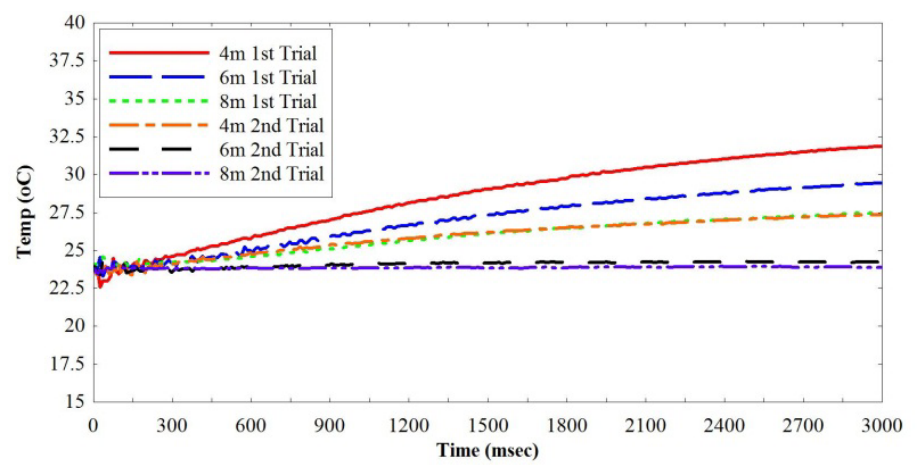

Figure 5: $\quad$ Internal temperature at $4 \mathrm{~m}, 6 \mathrm{~m}$ and $8 \mathrm{~m}$ radial positions.

\subsection{Flux gauges}

Fig. 6 shows the recorded thermal flux for both trials. At $4 \mathrm{~m}$ the peak flux recorded for the first and second trials were $145 \mathrm{~W} / \mathrm{cm}^{2}$ and (approximately) $115 \mathrm{~W} / \mathrm{cm}^{2}$. At $6 \mathrm{~m}$ the peak flux values were $85 \mathrm{~W} / \mathrm{cm}^{2}$ and $40 \mathrm{~W} / \mathrm{cm}^{2}$ for the first and second trials. At $8 \mathrm{~m}$ the flux was approximately $30 \mathrm{~W} / \mathrm{cm}^{2}$ and $18 \mathrm{~W} / \mathrm{cm}^{2}$ for the two trials. Significantly higher flux values were recorded across the spectrum of the fireball during the first trial than the second trial. As the flux gauges were pointing vertically from the box they would not have been subject to the same radiation flux that the facing plates would have experienced. Future trials will use flux gauges at the front of the boxes.

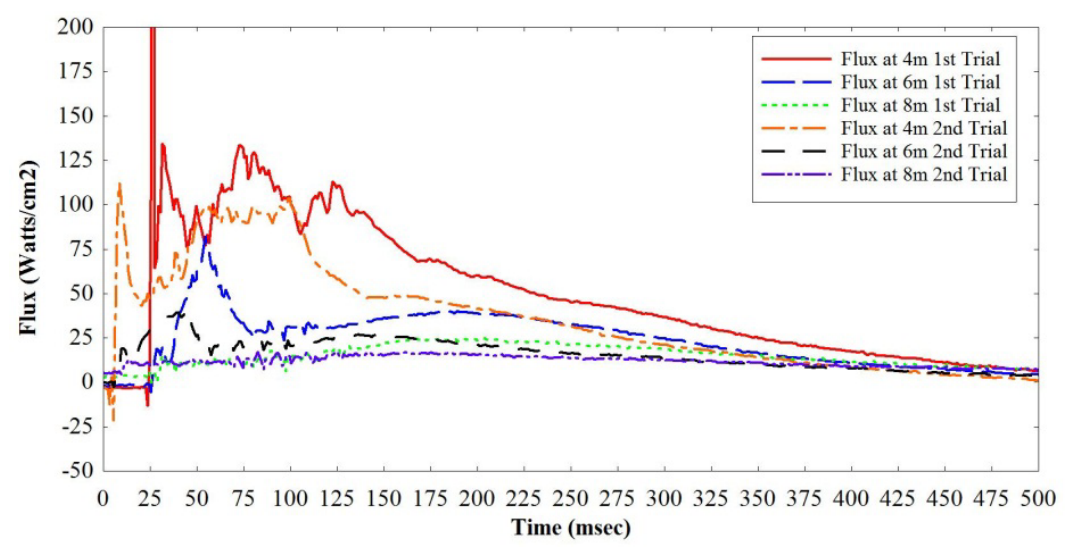

Figure 6: $\quad$ Recorded flux vs. time at $4 \mathrm{~m}, 6 \mathrm{~m}$ and $8 \mathrm{~m}$ radial positions.

\subsection{Reflected pressure}

The pressure gauges were placed on the front of the boxes adjacent to the plates. Computational fluid dynamics (CFD) simulations were performed using Air3D 
[3] in order to compare the pressure/time history plots. Fig. 7 shows the reflected pressures for each trial at $4 \mathrm{~m}$ and $8 \mathrm{~m}$.

The recorded peak reflected pressures at $4 \mathrm{~m}$ facing the blast were $4.04 \mathrm{MPa}$ (Trial 1) and 4.29MPa (Trial 2), the predicted values were 5.72MPa (2D) and $2.66 \mathrm{MPa}(3 \mathrm{D})$. The difference between the $2 \mathrm{D}$ and $3 \mathrm{D}$ model values are due to the rarefaction of the blast wave around the side of the box. The 2D model assumes an infinitely wide box and therefore there is no diffraction and clearing around the box sides. The 3D model allows rarefaction and therefore the front peak reflected pressure is less. The double peak phenomena was observed at $4 \mathrm{~m}$ facing the blast which is speculated at being from the combustion products hitting the gauge followed by the region of compressed air.

The recorded peak reflected pressures at $8 \mathrm{~m}$ facing the blast were $0.82 \mathrm{MPa}$ (Trial 1) and $1.14 \mathrm{MPa}$ (Trial 2), the predicted values were $0.77 \mathrm{MPa}(2 \mathrm{D})$ and $0.47 \mathrm{MPa}(3 \mathrm{D})$. Fast Fourier transform smoothing of the high peak for Trial 2 gives a value of approximately $0.85 \mathrm{MPa}$.

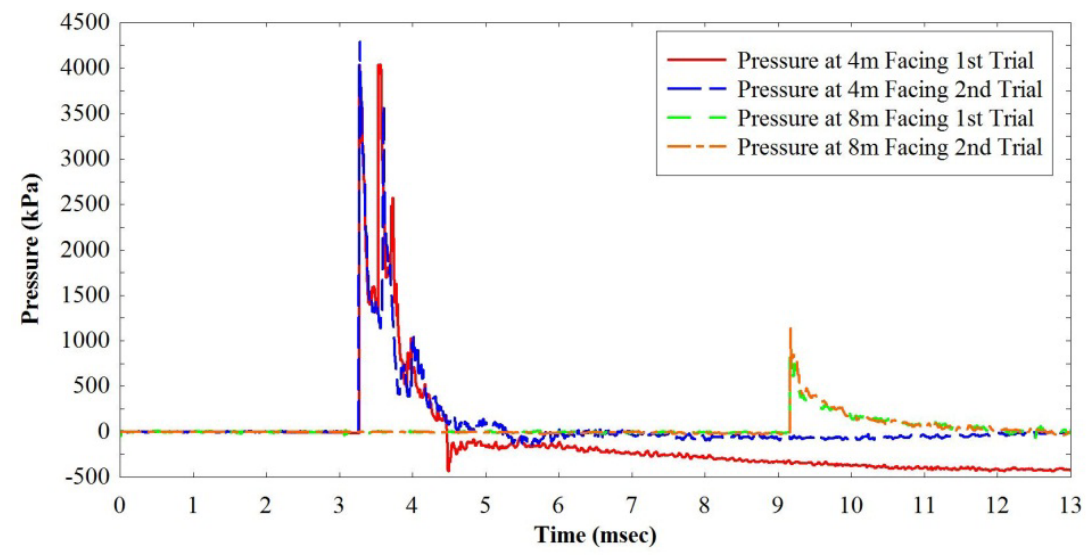

Figure 7: $\quad$ Reflected pressure at $4 \mathrm{~m}, 6 \mathrm{~m}$ and $8 \mathrm{~m}$ radial positions.

The correlations between blast pressures for both trials are reasonable, showing good reproducibility between the tests. Both gauges at $4 \mathrm{~m}$ show a double peak, the most suitable explanation for which is the pressure from the detonation of the products followed by the compressed air. At $8 \mathrm{~m}$ a second peak can also be seen at $20 \mathrm{msec}$, this phenomenon is termed the "second shock" or "termination shock" when a smaller pressure front has been reflected back off the explosive products and propagates out behind the main shock front.

At $4 \mathrm{~m}$ facing away the peak reflected pressures recorded were approximately $0.28 \mathrm{MPa}$ for Trial 1 and $0.32 \mathrm{MPa}$ for Trial 2. The predicted Air3D (3D) peak pressure was $0.35 \mathrm{MPa}$. During the first trial at $4.5 \mathrm{msec}$ the gauge appears to fail and records unrealistic negative pressure readings thereafter. 


\subsection{Recorded strain}

Fig. 8 shows the maximum recorded strains in the steel plates. The strain gauge plots show a significant difference between the two trials. This is due to the zero visible deflection exhibited by the plates facing away in the second trial. The maximum strain experienced by the plate at $4 \mathrm{~m}$ settled at $750 \mu$ strain whereas the equivalent strain experienced by the plate at $4 \mathrm{~m}$ from the second trial settled just above $300 \mu$ strain, as the plates facing away experienced no permanent deformations this value can be attributed to a gauge fault.

At $25 \mathrm{msec}$ there was a significant electrical disturbance which considerably affected the strain gauge results for both trials. This resulted in the plots showing unrealistic peak strains at this time. For the plate at $4 \mathrm{~m}$ in the first trial, if the line is extrapolated back towards that event we see that it curves up to approximately $1300 \mu$ strain this is equivalent to $262 \mathrm{MPa}$ stress (approximate yield strength). The other curves show a similar pattern; therefore we can deduce that the peak plate deformations were larger than the final settled deformations.

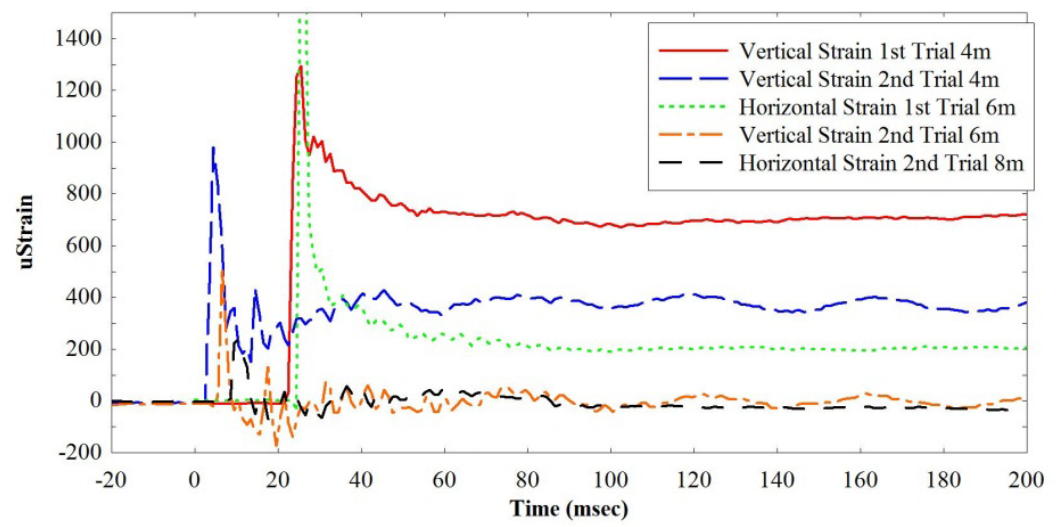

Figure 8: $\quad$ Maximum strain at $4 \mathrm{~m}, 6 \mathrm{~m}$ and $8 \mathrm{~m}$ radial positions.

The strains recorded by the individual gauges rotated at $0^{\circ}, 45^{\circ}$ and $90^{\circ}$ within each rosette gauge were different indicating non-homogenous plate deformations. This may be attributed to varying tightness of bolt, inaccuracy of plate dimensions or a non-planar wave hitting the plates. There are noticeable oscillations indicating a dynamic response of the plates.

\subsection{Deflected shapes}

Fig. 9 shows a plot of the deflected shape of the plates for both trials at $4 \mathrm{~m}$ and $6 \mathrm{~m}$ facing the blast, recorded manually with a Vernier calliper. The profile lines are $10^{\text {th }}$ order polynomial fits to the deflections measured across the plates vertically and horizontally. The maximum deflection at $4 \mathrm{~m}$ was $10.5 \mathrm{~mm}$ for trial one and $7.5 \mathrm{~mm}$ for trial two. The maximum deflection at $6 \mathrm{~m}$ was $5.25 \mathrm{~mm}$ for trial one, the deformations in the plate at $6 \mathrm{~m}$ from the second trial and $8 \mathrm{~m}$ for both trials were too small to be measured accurately with the Vernier calliper. No permanent deformations were observed on the plates facing away from the blast. 
The magnitude of the deformations in the plates facing the blast during the second trial was significantly less than the first trial. Similar patterns regarding the drop in magnitude between the two trials have been noted in other gauges. Reasons for the difference could be due to the unknown and volatile nature of the fireball, reproducibility of trial and fixity of bolts.

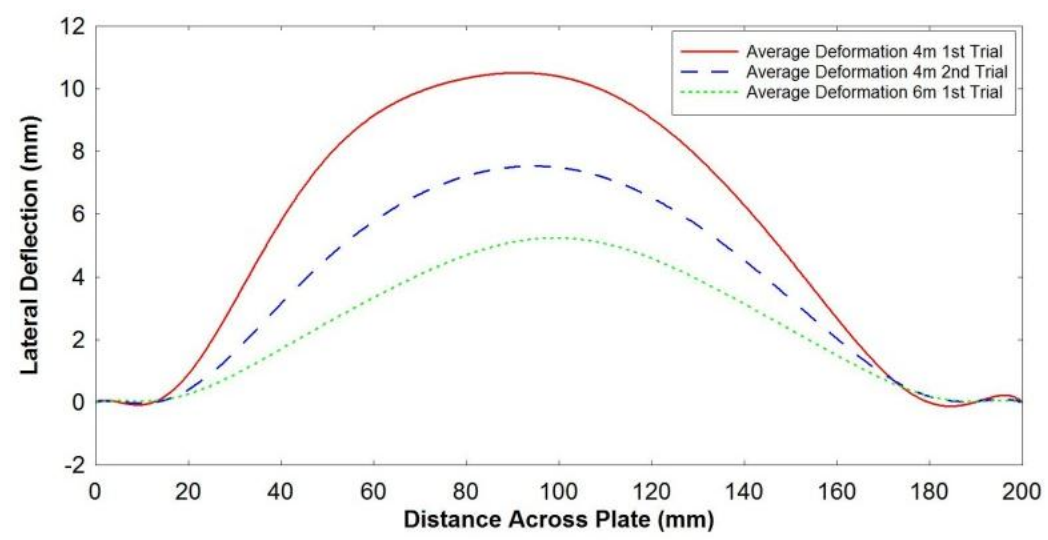

Figure 9: Average maximum plate deflections at $4 \mathrm{~m}$ and $6 \mathrm{~m}$ radial positions.

\section{Numerical modelling}

The FEA software LUSAS was used to construct the models of the $2 \mathrm{~mm}$ thick steel plate from the arena trials (Fig. 10). The element used was a HX8M linear solid element with a fast multifrontal direct solver, suitable for a coupled thermal and structural non-linear analysis. The non-linear solver used was total Lagrangian. Data from the recorded and predicted pressure vs. time histories were normalised then applied as load curves in LUSAS relating to the peak values inputted as a global distributed loads or prescribed temperatures.

The specified yield strength of the modelled steel was $264 \mathrm{MPa}$ with a plastic elongation phase of $20 \%$ strain. The yield strength is taken from the static tensile

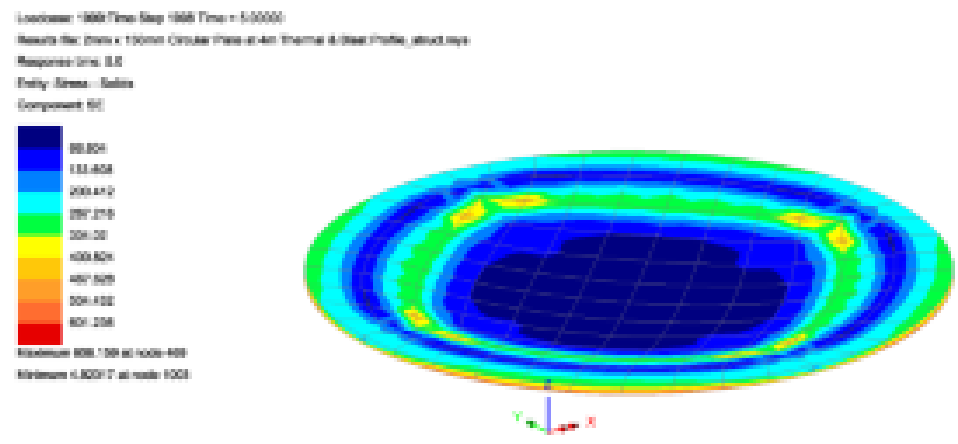

Figure 10: $\quad$ Extract from LUSAS modelling of $2 \mathrm{~mm}$ circular plate. 
tests multiplied by a dynamic increase factor (DIF) of 1.6 to take account of the high velocity load applied [4]. The temperature loads used in the models were taken directly from the recorded values and the pressure loads were taken both from the CFD predictions and gauges.

\section{Model results and analysis}

The following deflections and stresses are taken at the centre of the modelled plates at the position of maximum deflected shape and equivalent stress.

\section{$5.14 \mathrm{~m}$ plate facing blast (recorded trial pressures)}

Fig. 11 shows the deflection profile history at $4 \mathrm{~m}$ facing the blast. The deflection history profile of the plate with the combined thermal and blast loads is equal to the deflection history of the plate with the blast load only indicating that at this distance from the centre there are minimal synergistic effects. The plate in the thermal only model deflects to a peak of $6 \mathrm{~mm}$ then settles at $1.5 \mathrm{~mm}$. The thermal load is applied much later than the blast pressure; therefore in the combined model the plate has already deformed and reached its peak stress from the blast pressure by the time the thermal load is applied causing no further damage.

The recorded final deflection of the plates from the trials was: $10.5 \mathrm{~mm}\left(1^{\mathrm{st}}\right)$ and $7.5 \mathrm{~mm}\left(2^{\text {nd }}\right)$. The final deflected shapes predicted by the numerical models were approximately $8.5 \mathrm{~mm}(1 \mathrm{st})$ and approximately $7.5 \mathrm{~mm}\left(2^{\text {nd }}\right)$. Despite the predicted and numerical values not matching for the $1^{\text {st }}$ trial the $2^{\text {nd }}$ trial values were equal. The overall comparability of the predicted and actual values gives confidence for using LUSAS for the preferred non-linear, coupled analysis on whole structural sections. The reasons for the difference in the modelled and recorded deflections can be attributed to fixity of plates, volatility of fireball environment and accurate representation of loads within fireball.

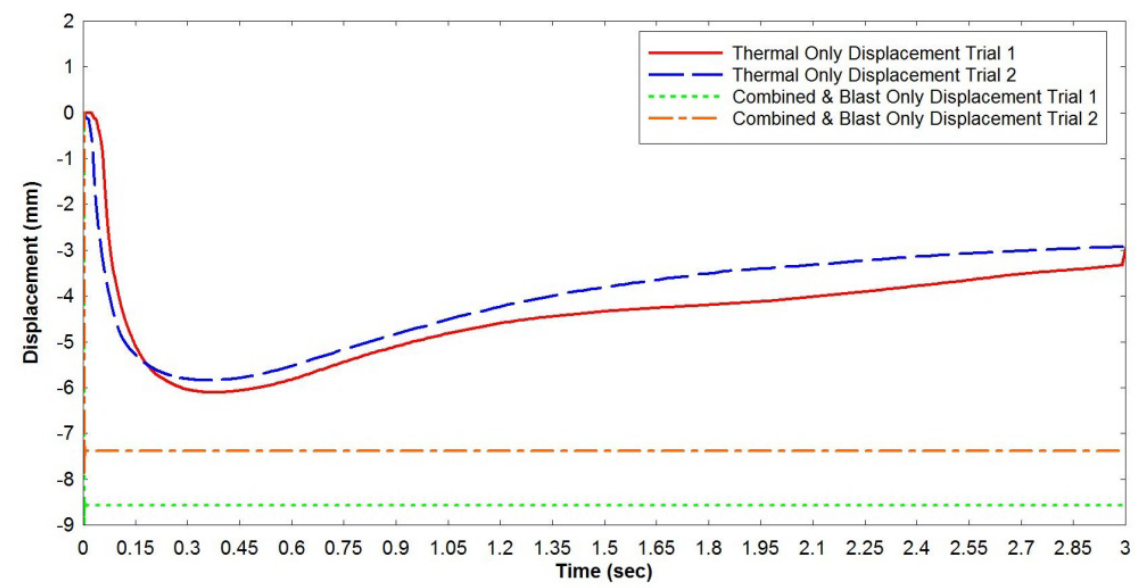

Figure 11: Displacement at $4 \mathrm{~m}$ facing blast combined and thermal. 
The stress response of the plate to the blast and the combined loads is almost identical to the deflected profile. The peak stress reached is approximately $350 \mathrm{MPa}$.

\section{$5.26 \mathrm{~m}$ plate facing blast (using Air3D pressures)}

Figs. 12 and 13 show the modelled deflected shapes of the plate facing the blast at $6 \mathrm{~m}$. There were no pressure gauges at this location therefore the pressure used in conjunction with the recorded temperature was taken from the CFD analysis.

The blast only displacement is similar to the actual final deflected shape. The $2 \mathrm{D}$ final deformation was approximately $5.5 \mathrm{~mm}$, which is very close to the $6 \mathrm{~mm}$ actual permanent deflection.

The combined pressure and temperature deflected plot has several interesting features. A notable high deformation of approximately $2.75 \mathrm{~mm}$ (2D) followed by a decrease and a noticeable harmonic response $(380 \mathrm{~Hz})$ followed by a second increase in deformation (peaking at $2.25 \mathrm{~mm}$ ) in line with the increase in temperature. If the deflection is extrapolated from $3 \mathrm{sec}$ the final deflected shape would be nearer $1.5 \mathrm{~mm}$.

This graph is the best evidence that there may have been some type of synergistic response in the plates in this trial. It is difficult to model the response of the plates more precisely as the exact time of arrival of the blast and thermal loads is unknown at this location.

The thermal only graph follows a similar trend to the thermal and blast (without the initial deflection from blast) peaking at approximately $1.65 \mathrm{~mm}$. There is a significant difference between trial 1 and trial 2 response. There is a difference in the recorded temperatures between the two trials but the observed response is unusual compared to the difference in temperatures. The plots of stress follow similar patterns at the deflections with peak values of $385 \mathrm{MPa}$ for the combined thermal and blast case.

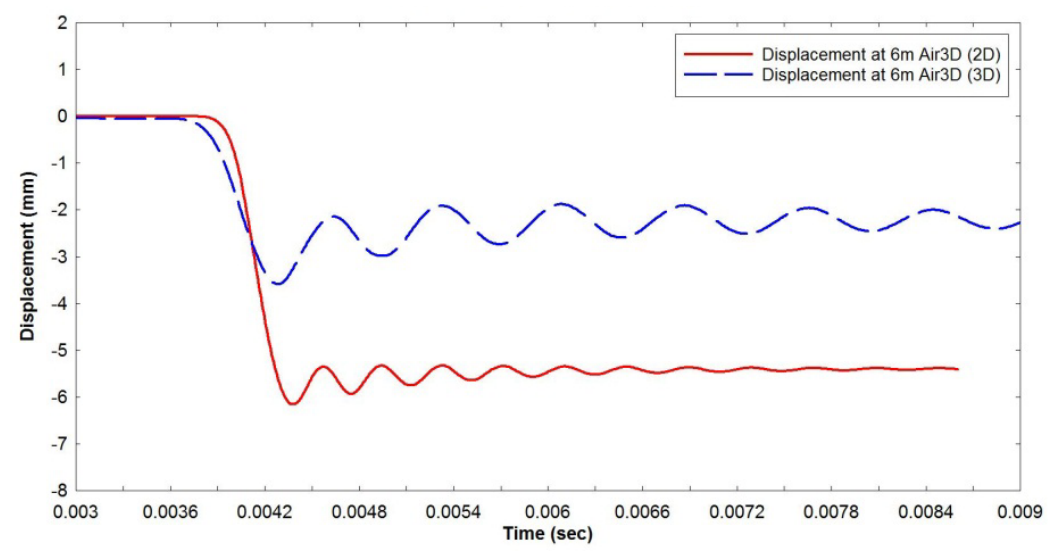

Figure 12: Displacement at $6 \mathrm{~m}$ facing blast only. 


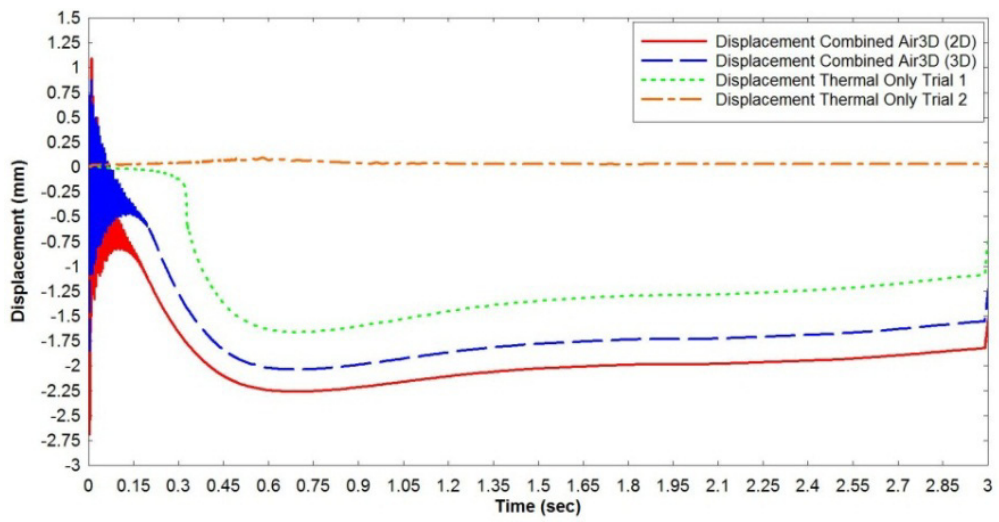

Figure 13: Displacement at $6 \mathrm{~m}$ facing blast combined and thermal.

\section{$5.38 \mathrm{~m}$ plate facing blast $\left(1^{\text {st }}\right.$ and $2^{\text {nd }}$ trial pressures and Air3D)}

Fig. 14 shows the plot of deflections for the plates at $8 \mathrm{~m}$ facing the blast. After each trial there was no visible permanent deflection on the plates. The combined thermal and blast peaks at $2 \mathrm{~mm}$ then settles to $0.3 \mathrm{~mm}$, a second peak is observed at $0.03 \mathrm{sec}$, this could be due the second shock. The thermal only plot shows opposing responses for the first and second trial. The profile of the stress plots were identical to the displacement, with peak stresses of approximately $275 \mathrm{MPa}$ for both the combined and blast only cases, which corresponds to the yield stress of the steel with a DIF applied. The peak stresses from the Air3D pressure models were $190 \mathrm{MPa}$ before settling in a similar profile to the deflected shape.

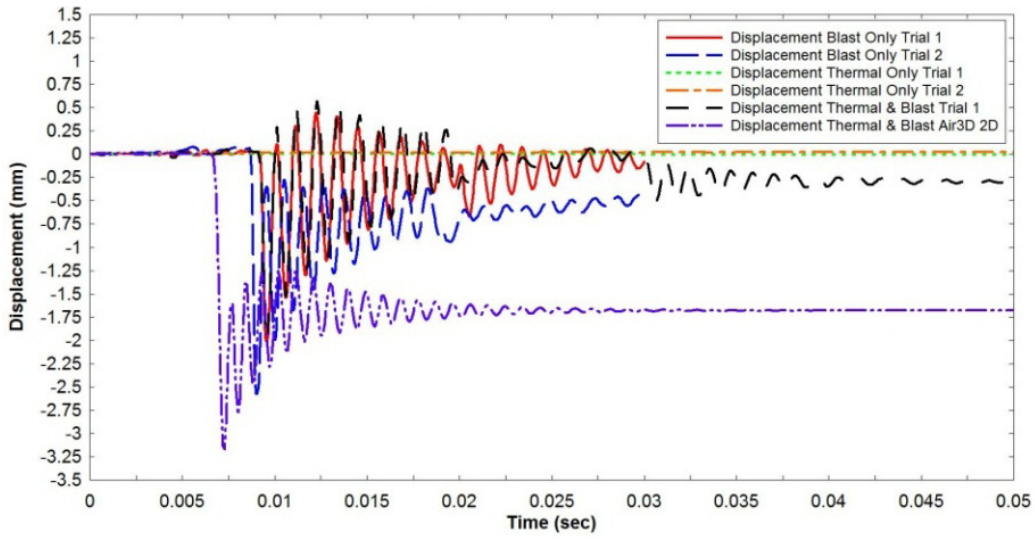

Figure 14: Displacement at $8 \mathrm{~m}$ facing, combined, thermal and blast only.

\section{Conclusions}

In this paper results from trials gauging the fireball of a $41 \mathrm{~kg}$ TNT explosive event have been presented. The structural response of $2 \mathrm{~mm}$ thick plates within 
the fireball are described alongside the numerical analysis of the plates to observe any thermal and blast synergistic response. The plates at $4 \mathrm{~m}$ displayed minimal synergistic response as the deformations and stresses initially caused by the blast wave did not increase upon arrival of the later thermal load.

Synergistic response was observed in the numerical models of the plates at $6 \mathrm{~m}$. The plates had lower stresses from the blast and were subsequently heated. It was difficult to confirm if such a response occurred in the actual plates as there were no pressure gauges at $6 \mathrm{~m}$ and the strain gauges did not show movement after the first $100 \mathrm{msec}$. The plates at $8 \mathrm{~m}$ did not experience any permanent deformations but numerical models show elastic deformations and oscillations. LUSAS proved a suitable analytical tool for modelling the actual deformations in the non-linear coupled environment.

It has proved difficult to accurately measure the deflection time history of the plates using strain gauges, therefore the use of accelerometers, laser deflection meters and high speed cameras will be adopted for future work. The heavy structural boxes performed well and survived the trials. Further developments are required to provide flux gauges and/or thermocouples on the front of the boxes which will record the direct thermal radiation and convection. Once the boxes have been improved they will be used again for future combined thermal and long duration blast experimentation.

This paper shows that there is minimal synergistic response in structures subject to explosions of a size equivalent to $41 \mathrm{~kg}$ TNT. Features of fireball development such as a double pressure peak relating to expansion of combustion products and region of compressed air have been highlighted. The deformed shape of the plates from the numerical analysis correlates well with the experimental results. The benchmarking of the numerical tool to actual results has provided the researcher with the confidence in the tool for use with full structural elements exposed to large yield explosive environments.

\section{Acknowledgement}

The author acknowledges that all results and data recorded and discussed in this paper are $\mathrm{MoD}$ results obtained at $\mathrm{MoD}$ facilities.

\section{References}

[1] Clough, L.G., Gauging the Fireball: Simulation and Testing. Proc. of the $15^{\text {th }}$ International Symposium on Interaction of the Effects of Munitions with Structures, Clubley. S.K., Potsdam, Germany, 2013.

[2] LUSAS, www.lusas.co.uk

[3] Rose, T.A., An Approach to the Evaluation of Blast Loads on Finite and Semi-Infinite Structures. PhD Thesis, Cranfield University, Royal Military College of Science.

[4] Yandzio, E. \& Gough, C., Protection of Buildings Against Explosions, The Steel Construction Institute: Ascot, pp. 60, 1999. 